\title{
PREFACE: BEYOND THE DESIGN METAPHOR
}

The metaphor of design, with the organism as artifact, is at the heart of Darwinian evolutionary biology.

- MICHAEL RUSE, 2003, DARWIN AND DESIGN

Many evolutionary biologists today are in the rather peculiar position of denying design in their battle with "intelligent design" proponents over the teaching of evolution in the schools, while at the same time they embrace a design metaphor for understanding the features of organisms. The basic structure of the approach is simple: because of past natural selection, organisms appear "as if" designed for the end of survival and reproduction, and thus we can think of them "as if" they were designed-but please don't think that they actually were designed. This position seems uncomfortable, if not absurd.

The relation of current evolutionary biology to the "design problem" is indeed rather strange. We deny evolution any teleology, any goal-directedness; we are convinced that natural selection and mutation are mechanistic evolutionary processes, which can't foresee the future. Yet we use past natural selection as a way to explain the current adaptedness of organisms, in much the same way that pre-Darwinian natural theologians invoked the past actions of the Creator-as exemplified by Paley's (1802) famous metaphor of the Creator as divine watchmaker. To put this another way: the general position of evolutionists is that Darwin destroyed the design argument. The implication is that the design argument was valid in the absence of natural selection, that natural selection was needed to fill a void that existed prior to Darwin, a void previously filled by the Creator: "Paley was correct to choose design over chance, but he did not know that there was a natural as well as a transcendent source of design" (Scott 2005, 83).

What I attempt to show in this book is that the analogy between natural selection and a designer is both pernicious and unnecessary. The design argument was not valid before Darwin: it had been destroyed by Lucretius, Hume, and a host of 
others, even in the absence of evolution. I argue that the design metaphor, rooted in the analogy between natural selection and the Creator, has resulted in a curiously "squishy" structure to current evolutionary theory, including the theory of mathematical population genetics, and that this "squishiness" has contributed to the persistent nature of many of the major controversies in evolutionary biology. Among these controversies are the validity of adaptationism, the relative roles of natural selection and genetic drift in evolution, the levels of selection, and even the proper definition of such fundamental terms as adaptation, fitness, and natural selection itself.

I believe that we can achieve clarity on many problematic issues by connecting evolutionary theory with the antiteleological theories of the past, rather than the natural theological ones. We can thereby achieve a more balanced structure for evolutionary theory, a structure in which natural selection is reconnected with ecology and integrated with other evolutionary "forces," in which "internal selection" is accorded a place as important as "external selection," in which mechanisms that generate novelty can play their roles alongside mechanisms that spread the novelties that arise.

For me, the bridge to making this connection, and thus to dealing with the problem of teleology, comes in the form of Georges Cuvier's (1769-1832) principle of the "conditions for existence" (conditions d'existence): anything that exists must be doing so by virtue of the fact that it is satisfying its conditions for existence. Cuvier has traditionally been seen as the conservative antievolutionist, who used his power and prestige to squash the prescient Jean-Baptiste Lamarck and Etienne Geoffroy Saint-Hilaire (the evolutionists of his day). It is rather ironic, then, that his principle may help move evolutionary theory beyond the teleology implicit in Darwinian natural selection.

To explain the origins of this book, I must indulge in some personal history. When I arrived at the Museum of Comparative Zoology in fall 1984, a vigorous controversy raged the halls, between Steve Gould and Richard Lewontin, on the one hand, and E. O. Wilson, on the other. This controversy centered on the validity of what Gould and Lewontin termed "adaptationism" and the "Panglossian paradigm" - the assumption that natural selection rules evolution and that, as a result, all structures and behaviors of organisms can be understood as adaptations, evolved under natural selection for a specific function or functions. I had come to join Pere Alberch's lab, which focused on the role of developmental constraints in morphological evolution, work closely allied to Gould and Lewontin's critique of adaptationism. Yet as I thought more about the issues involved, it seemed to me that both sides of the debate had merit. This was not just a controversy to be entered into, but rather a problem I might be able to solve-a presumptuous idea, but that's how young grad students are.

I began to read widely in the historical and philosophical aspects of this debate, which in morphology has always been expressed as that over the primacy of form 
versus function. One day, as I rode my bicycle home from the lab, I was mulling over Cuvier's principle. It suddenly occurred to me that Cuvier's principle of the conditions for existence could be seen as identical to Darwin's principle of natural selection, in the sense that those organisms that don't satisfy their conditions for existence are summarily "selected against."

This book is the further development of this thought, which I believe offers a promising approach to resolving some of the persistent controversies in evolutionary biology. As I have come to realize, the principle of natural selection plays at least two different roles in evolutionary biology. On the one hand, it can be conceived of as the principle of differential survival and reproduction of genetic variants due to their differential adaptedness-that is, as a mechanism of evolutionary change in populations. I call this the principle of evolution by "narrow sense" selection; it is the common conception and is clearly not the same as Cuvier's principle.

On the other hand, the principle of natural selection can be conceived of as a principle of interpretation or understanding applied to the evolutionary process; a principle that can be applied at any level. This conception (when teleological associations have been removed) is indeed structurally equivalent to Cuvier's principle. I call this the principle of "broad sense" selection. Whatever the path of evolution from time A to time B, all organisms (as well as genes, cell lineages, characters, species, etc.) participating in this path must have been satisfying their conditions for existence. We can use this knowledge to guide our investigation. This is what I mean when I say that the principle of the conditions for existence functions as a principle of interpretation or understanding. The conditions for existence are the boundary conditions within which evolution must occur.

I argue that both conceptions of the principle of natural selection are valid, but that confusion between them frequently gives interpretations of evolution by natural selection a teleological flavor. Unlike the conditions for existence, which admit no exceptions, the mechanism of natural selection is only one factor in evolution, however important it may be. By considering the mechanism or process of narrow sense natural selection responsible for the entire path of evolution, one in effect treats the end result achieved as the goal of the process. This is the standard view that since the eye is adapted for seeing, its structure can be explained as the end result of a process of selection for seeing.

Gould himself was one of the worst in this respect: by asking us to consider each trait as an "adaptation" (originating by natural selection for its proper function), a "nonaptation" (originating somehow else), or an "exaptation" (originating by natural selection of a distinct adaptation or nonaptation), he accepted the division of the organism into discrete traits, some of which were the goal of past natural selection, some of which weren't. Gould had no difficulty in considering the eye an adaptation for seeing. Nevertheless, given that other evolutionary factors must have 
played some role in the origin of the eye over millions of years (though how great a role can certainly be debated), it simply can't be true that selection for seeing was responsible for all the change that occurred along the path to the present form.

The conditions for existence, unlike past selection, are subject to empirical investigation. For example, whatever mechanisms were responsible for the changes involved in the evolution of the eye-and I suspect that selection for seeing played a prominent if not exclusive role-it is clear that all the organisms along this path were able to see well enough to obtain the information necessary to satisfy their conditions for existence. This observation leads naturally into studies on the role of vision in the life of current organisms, with inference back to ancestors of living taxa. Such inference may not seem profound, because it does not provide a causal account of the evolution of vision, but it does enable us to understand how it was that these organisms left descendants at all, and thus stayed in the evolutionary game.

Although I am trying to avoid some of the subtleties of the issues involved here (there will be time enough for them in the body of the book), it is important to note another, related use of the principle of the conditions for existence-a use that is more closely connected with the mechanism of narrow sense natural selection. This use of the principle deals with the conditions for continued existence (persistence) of characters in populations. What both Darwin and Wallace pointed out was that for any feature ("variation") or variant type ("variety") to persist in a population, that feature or type must satisfy its conditions for existence. They assumed in particular that a feature or type will generally persist only if it is associated with greater success in the struggle for existence than its alternatives. This might be called the Darwin-Wallace principle; it is here that their thought clearly went beyond Cuvier's focus on the individual organism.

A classic example of such reasoning is the constraints we accept on our thinking about the dorsal plates of Stegosaurus. The function of these plates has been debated, but the assumption that they must have had some function can be justified on the basis that if they did not, they would not have persisted in the population. Of course, we can also assume that the individual stegosaurs must have been satisfying their conditions for existence as organisms.

I do not claim originality for any of the ideas in this book but seek only to put existing ideas in a more rigorous conceptual framework, a framework that helps clarify the interrelationships among the basic concepts of evolutionary biology. I am all too aware of my own limitations and how they have affected my ability to produce the book I wanted to. Nevertheless, once I got started, I had to write this book, if only to get it out of my system - and to raise questions that I think have not been satisfactorily answered by the debate as it stands today. I will be gratified 
if it encourages people to reexamine for themselves the relation among functional explanation, adaptedness, and Darwinian natural selection.

This book owes an intellectual debt to far too many people to mention individually, and no doubt to some I have now forgotten. Nevertheless, I must acknowledge the importance of my adviser, the late Pere Alberch, and my fellow Typologists. I owe to them my introduction to the historical and philosophical issues involved and, indeed, to "philosophical natural history" in general. Steve Gould and Richard Lewontin opened my eyes to the problem of neo-Darwinian teleology. Leon Croizat and Dov Ospovat helped me see just how this teleology enters the theory of natural selection and where this teleology came from, thus pointing the way to how to get beyond it. Finally, E. S. Russell introduced me to Cuvier and to a functionalism not rooted in past natural selection. Without all of these people, this book could never have been written.

I am also grateful to the many people have read some or all of the book at various stages of its preparation and given me comments. I would like to thank in particular Alan de Queiroz, Megan Donahue, A. W. F. Edwards, Richard Lewontin, Amy McCune, Peter McLaughlin, Will Provine, Karen Reiss, Phillip Sloan, Philippe Taquet, and J. Scott Turner. Michael Wade and Robin Waples helped by their criticism of a draft of chapter 8 submitted to (and rejected by) Evolution.

Two chapters previously appeared in print in different form: material in chapter 2, previously published as Reiss (2005), is included with kind permission from Keith R. Benson, editor in chief, History and Philosophy of the Life Sciences; material in chapter 7, previously published as Reiss (2007), is included with kind permission from Springer Science+Business Media.

A key aspect of my approach has been to include some lengthy quotes from historical sources. Excerpts from the following works are reprinted by kind permission of the publishers listed. Xenophon (1965), Recollections of Socrates and Socrates' Defense before the Jury, translated by A. S. Benjamin, excerpts reprinted by permission of Pearson Education, Inc., Upper Saddle River, NJ; Aristotle (1952), Physica, translated by R. P. Hardie and R. K. Gaye, excerpts reprinted by permission of Oxford University Press; Lucretius (1995), On the Nature of Things: De rerum natura, translated by A. M. Esolen, excerpts reprinted by permission of The Johns Hopkins University Press; Descartes (1985), The Philosophical Writings of Descartes, Vol. 2, translated by J. Cottingham, R. Stoothoff, and D. Murdoch, excerpts reprinted by permission of Cambridge University Press; Stewart and Kemp (1963), Diderot, Interpreter of Nature: Selected Writings, translated by J. Stewart and J. Kemp, excerpts reprinted by permission of International Publishers Co., New York; Kant (1987), 
Critique of Judgment, translated by W. S. Pluhar, excerpts reprinted by permission of Hackett Publishing Company, Inc.; Rudwick (1997), Georges Cuvier, Fossil Bones, and Geological Catastrophes: New Translations and Interpretations of the Primary Texts, translated by M. J. S. Rudwick, excerpts reprinted by permission of University of Chicago Press; Bernard (1927), An Introduction to the Study of Experimental Medicine, translated by H. C. Greene, excerpts reprinted by permission of Dover Publications, Inc.; Fisher (1930a), The Genetical Theory of Natural Selection, excerpts reprinted by permission of Oxford University Press; Letteney (1999), Georges Cuvier, Transcendental Naturalist: A Study of Teleological Explanation in Biology, excerpts from this unpublished $\mathrm{PhD}$ dissertation included by kind permission of Michael Letteney. In all cases, copyright still obtains and all rights are reserved to the copyright owner.

I would like to thank Julia Graham and the rest of the Interlibrary Loan staff at the Humboldt State University library for going beyond the call of duty in helping me obtain some of the older literature. Valerie Budig-Markin graciously reviewed and corrected my French translations. Chuck Crumly, my editor at University of California Press, has been supportive and patient beyond any reasonable limit. Francisco Reinking and Kate Hoffman at the Press, and Aline Magee and Laura Larson of Michael Bass Associates, were a great help with the logistics of preparing the final manuscript. A grant from Humboldt State University Sponsored Programs Foundation helped with publication costs. Finally, my wife, Karen Reiss, has been there for me throughout. I'd especially like to thank her for confiscating the nascent manuscript to prevent me from working on it, thus allowing me to finish my doctoral dissertation-and for later being willing to give it back. 